$$
\text { BNL - } 69623-\mathrm{CP}
$$

Submitted to: PAC ${ }^{\mathrm{C}} 03$

May 12-16, 2003, Portland, Oregon

\title{
The AGS Electrostatic Septum
}

\author{
J Hock, T. Russo, J. Glenn, K. Brown
}

\section{INTRODUCTION}

The previous slow beam extraction electro static septum in the AGS was designed in 1981. Research documented at the Fermi Laboratory was used as the base line for this design $n_{1}$. The septum consisted of a ground plane of .002" diameter wire tungsten-rhenium alloy $(75 \% \mathrm{~W} 25 \% \mathrm{Re})$ with a hollow welded titanium cathode assembly. The vacuum chamber is stationary and the septum is moved with a pair of high vacuum linear feed throughs.

After years of beam time, the frequency of failures increased. The vacuum system design was poor by today's standards and resulted in long pump down times after repairs. The failures ranged from broken septum wires to a twisted cathode. In addition to the failures, the mechanical drive system had too much backlash, making the operating position difficult to repeat. The new septum needed to address all of these issues in order to become a more reliable septum.

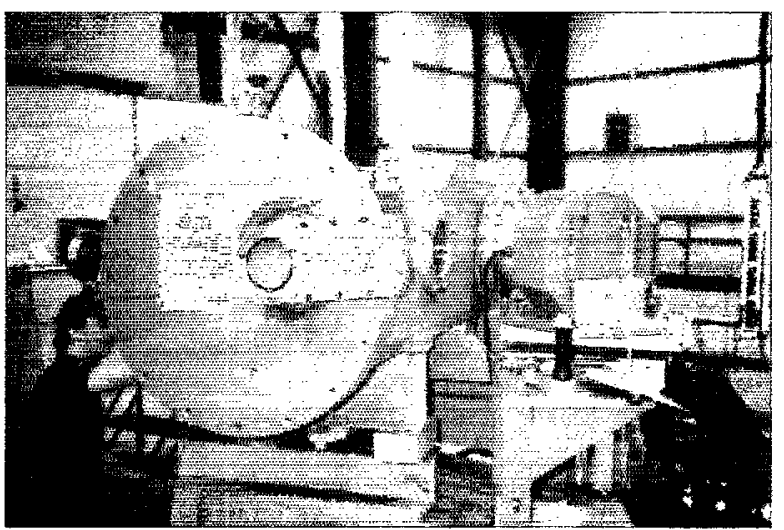

Figure 1: The Old AGS Electro Static Septum

\section{VACUUM CHAMBER}

The vacuum chamber material was changed to stainless steel with knife-edge flanges and copper gaskets. The septum assembly was slid into the chamber on linear bearings, so the septum could be removed quickly from the chamber during maintenance. All materials used in the septum were compatible for high vacuum. All mating surfaces were vented and all blind tap holes were assembled with vented bolts. The pump down time was reduced from 6 hours to less than an hour.

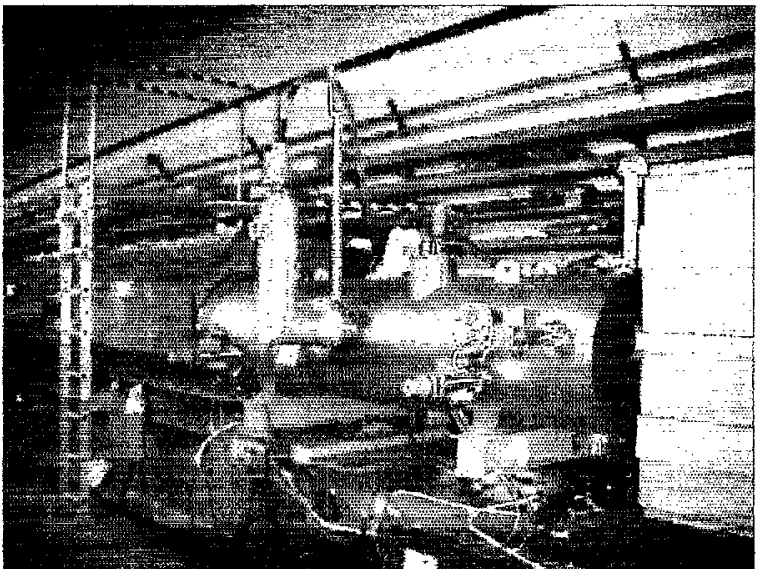

Figure 2: The New AGS Electro Static Septum

\section{LINEAR ACTUATORS}

The mechanical linear actuators were designed with all the control components (limit switches, feedback potentiometer, and drive motor) mounted to the same unit. The actuator is attached to the vacuum with a flange, and the septum with a pin, for quick removal from the high radiation area. The backlash was minimized by adding a tension spring on the septum assembly, opposite the linear drives, thus always loading the drive system in one direction. The feedback potentiometer was mounted directly to the actuator shaft with an anti-backlash gear.

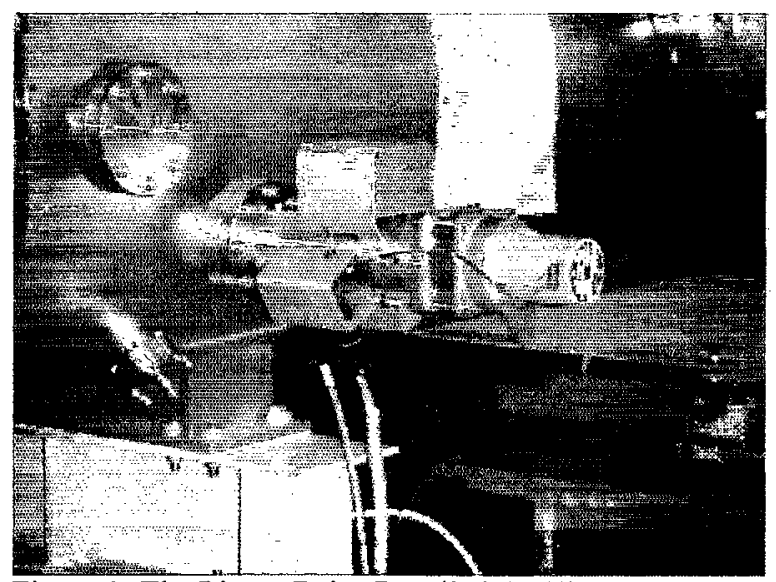

Figure 3: The Linear Drive Installed On The Septum 


\section{CATHODE}

The old cathode was a welded assembly made from tubular titanium, which was twisted, possibly from over heating during conditioning. The new cathode was made from a solid titanium rod, able to carry more current during conditioning.

\section{GROUND PLANE}

In an effort to prevent the proton beam from breaking the septum wire, the geometry and material of the wire was addressed. The wire was mounted to the septum on a c-shaped support between two tension springs. The spring tension provided stiffness to the fragile wire, minimizing its deflection induced by the electrical field, and pulls the wire away from the cathode if it brealss. The tensile load on the mire from the springs is small (25i) due to the small cross sectional area of the wire. The wire is attached to the springs by twisting a loop in the end of the wires. causing slight slippage at initial tensioning of the wire. A consistent wire length was difficult to maintain. The varying lengths of the wire, coupled with the varying properties of the springs vield different tensile load on the wires, hence different displacements caused by the $60 \mathrm{kV}$ electro static field. The different deflections of the wire meant that the gromnd plane was thicher then $.002 \%$.

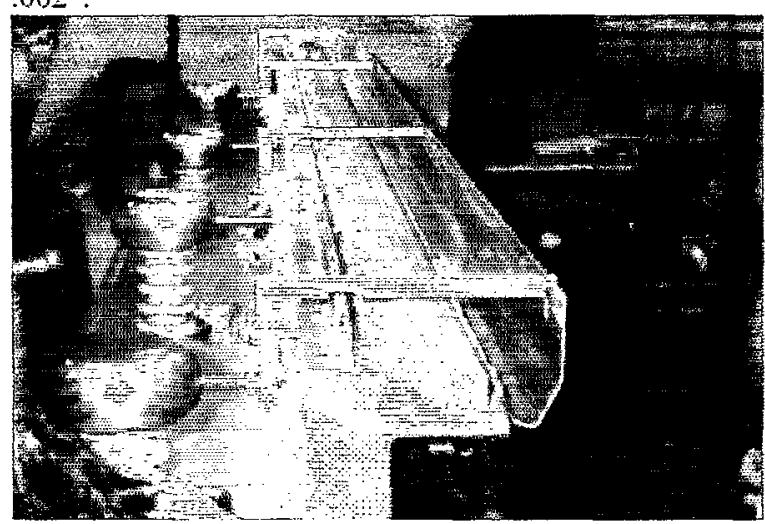

Figure 4: AGS Old Electro Static Septum

Several different shapes and materials were heat load tested using a defocused electron beam welder in a vacuum. Five tests were performed for each of the following test samples: .002 " diameter W $75 \%$ Re $25 \%$ alloy wire (the existing design), .002" by $.035^{\prime \prime} \mathrm{W} 75 \% \operatorname{Re} 25 \%$ alloy foil strip, $.001^{\prime \prime}$ by $.035^{\prime \prime}$ W $75 \% \operatorname{Re} 25 \%$ alloy foil strip, $.002^{\prime \prime}$ by $.035^{\circ} 3 \mathrm{Al}-$ $2.5 \mathrm{~V}$ Ti alloy foil strip, and $.001 "$ by $.035^{\prime \prime} 3 \mathrm{Al}-2.5 \mathrm{~V} \mathrm{Ti}$ alloy foil strip. The test fixture consisted of four foils of the same type, installed between a pair of springs. evenly spaced at $.125^{\prime \prime}$, and orientated so that the edge of the foil shadows electron beam. The .002 diameter wire test samples were set up the same as the foils except eight wires were evenly spaced at $.063^{\prime 2}$. The beam was set at different power settings and the exposure time was recorded. From the results of this test (listed in Table 1), the .001" thick by .035" W $75 \%$ $\operatorname{Re} 25 \%$ alloy was the best choice. Further research of the tungsten rhenium alloy showed the $\mathrm{W} 95 \% \operatorname{Re} 5 \%$ had the highest tensile strength of this alloy.2

The new AGS electro static septum uses a .001 " thick by .035 " wide $W 95 \% \operatorname{Re} 5 \%$ alloy foil strip. The large cross sectional area allows the foil to have a higher tensile load than the wire, yielding less displacement from the electro static force. The theoretical displacement for the foil is .0003" as compare to the wire $.003^{\prime \prime}$. The stiffer foil also reduces the displacement due to the different spring properties and lengths of the foil.

Although the foil strip septum is thinner, the total length of material is $26.25^{\circ}$ as compared to the wire, which is $3^{\prime \prime}$. The predicted losses at the septum will increase, but reduce the losses for the downstream slow beam extraction devices.

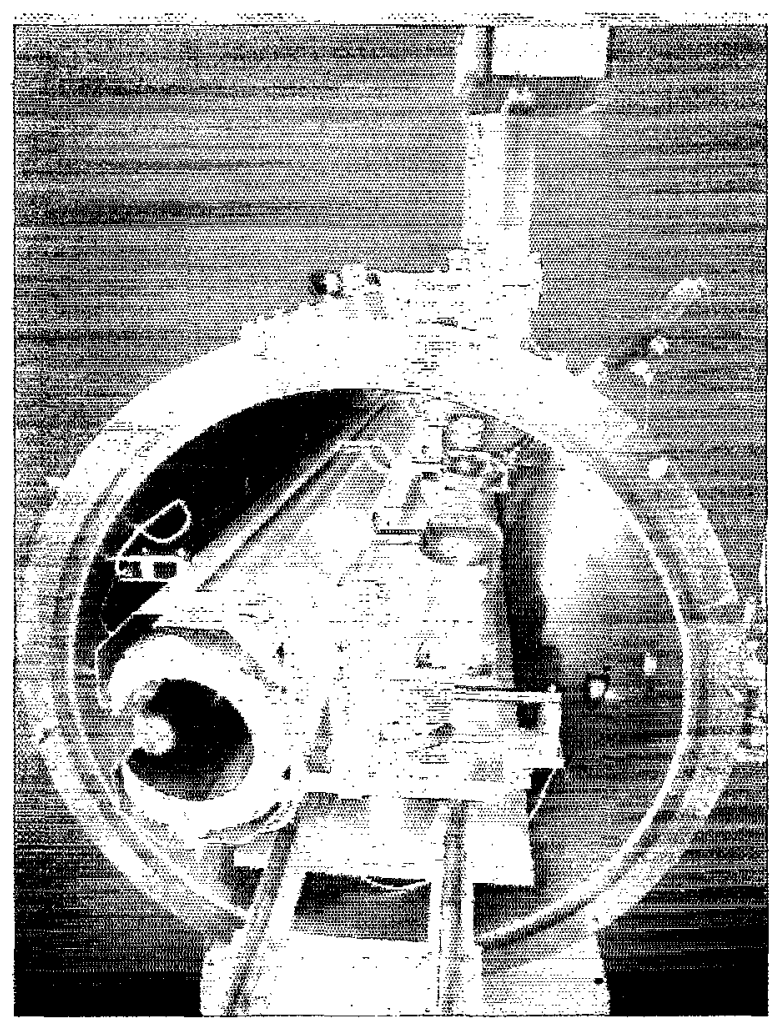

Figure 5: The New AGS Electro Static Septum 


\begin{tabular}{|c|c|c|c|c|c|c|}
\hline \multicolumn{7}{|c|}{ TABLE 1: SEPTUM HEAT LOAD TEST } \\
\hline TEST SPECRMAN & $\begin{array}{c}\text { BEAM } \\
\text { CURRENT } \\
\text { (mA) }\end{array}$ & $\begin{array}{l}\text { VOLTAGE } \\
(\mathrm{kV})\end{array}$ & $\begin{array}{l}\text { BEAM. } \\
\text { DIA. } \\
\text { (cm) }\end{array}$ & $\begin{array}{c}\text { BEAM } \\
\text { FLUX } \\
(\text { W/cm })\end{array}$ & $\begin{array}{c}\text { TMME } \\
(\mathrm{s})\end{array}$ & OBSERVATION \\
\hline $.002^{\prime \prime} \mathrm{BY} .035^{\prime \prime}$ & 0.7 & 90.6 & 0.2 & 2,020 & 2.5 & NO FAILURE \\
\hline W $75 \% \operatorname{Re} 25 \%$ & 0.7 & 90.6 & 0.2 & 2,020 & 3.5 & $3^{\mathrm{KD}}$ FOIL FAILED \\
\hline \multirow[t]{4}{*}{ FOIL STRIP } & 0.6 & 85.0 & 0.2 & 1,624 & 30.0 & NOFAחURE \\
\hline & 0.7 & 90.6 & 0.2 & 2,020 & 3.0 & $1^{\mathrm{ST}}$ FOIL FAILED \\
\hline & 0.6 & 88.0 & 0.2 & 1,682 & 9.5 & $2^{\mathrm{ND}}$ FOIL FAILED \\
\hline & 0.6 & 87.0 & 0.2 & 1,662 & 38.0 & $4^{\mathrm{HH}}$ FOIL FAILED \\
\hline $.001 "$ BY $.035^{\prime \prime}$ & 0.6 & 85.0 & 0.2 & 1,624 & 9.0 & $1^{\text {ST }}$ FOIL FAILED \\
\hline W 75\% $\operatorname{Re} 25 \%$ & 0.6 & 87.0 & 0.2 & 1,662 & 60.0 & NO FAILURE \\
\hline \multirow[t]{3}{*}{ FOIL STRIP } & 0.6 & 88.0 & 0.2 & 1,682 & 60.0 & NOFAILURE \\
\hline & 0.7 & 90.6 & 0.2 & 2,020 & 60.0 & NO FAILURE \\
\hline & 0.7 & 91.0 & 0.2 & 2,028 & 300 & NO FAILURE \\
\hline .002 DIA. WIRE & 0.6 & 85.0 & 0.2 & 1,624 & 0.0 & ALL 8 WIRES FAILED \\
\hline W $75 \% \operatorname{Re} 25 \%$ & $\overline{0.3}$ & 60.0 & 0.5 & 92 & 8.0 & ALL 8 WTRES FAПEED \\
\hline $.002 " \mathrm{BY} .035 "$ & .06 & 85.0 & 0.2 & 1,624 & 1.0 & ALL 4 FOILS FAILED \\
\hline \multicolumn{7}{|l|}{$\begin{array}{c}\text { 3A1-2.5V Ti } \\
\text { ALLOY }\end{array}$} \\
\hline \multicolumn{7}{|l|}{ FOIL STRIP } \\
\hline $.001 " B Y .035 "$ & 0.6 & 85.0 & 0.2 & 1,624 & 1.0 & ALL 4 FOILS FAILED \\
\hline $\begin{array}{c}\text { 3A1-2.5V Ti } \\
\text { ALLOY }\end{array}$ & 0.2 & 50.0 & 0.76 & 22 & 60.0 & NO FALURE \\
\hline \multirow[t]{6}{*}{ FOIL STRIP } & 0.3 & 50.0 & 0.5 & 76 & 60.0 & NO FAILURE \\
\hline & 0.3 & 50.0 & 0.25 & 306 & 5.0 & $1^{\text {ST }}$ FOIL FAILED \\
\hline & 0.3 & 50.0 & 0.4 & & 60.0 & NO FAILURE \\
\hline & 0.3 & 60.0 & 0.50 & 119 & 110.0 & $2^{\mathrm{ND}}$ FOIL FAILED \\
\hline & 0.3 & 60.0 & 0.50 & 92 & 40.0 & $3^{\mathrm{RD}}$ FOIL FALEED \\
\hline & 0.3 & 60.0 & 0.50 & 92 & 188.0 & $4^{\mathrm{TH}}$ FOL FALED \\
\hline
\end{tabular}

\section{CONCLUSION}

The new foil strip septum performed similar to the wire septum. As predicted the losses increased at the septum and was slightly reduce at the downstream extraction devices, but the overall extraction efficiency was unchanged. Due to problems with the positioning control circuit, caused by noise, it is unclear if the backlash was reduced. In addition, the leakage current gradually increased with beam time. During the 2003 shutdown the AGS electrostatic septum will be removed, inspected and repaired. Also the positioning control circuit will be fixed.

\section{REFERENCES}

1. J. Walton, et al, "An Improved Design For The Fermilab Septa", IEEE Transactions on Nuclear Science, Vol. NS-22, No.3, June 1975.

2. ASM Handbook, "Properties And Selection: Nonferrous Alloys and Special-Purpose Materials”, Vol. 2, p.580, October 1995. 